\title{
Evaluation of the new ESR network software for the retrieval of direct sun products from CIMEL CE318 and PREDE POM01 sun-sky radiometers
}

\author{
V. Estellés ${ }^{1,2}$, M. Campanelli ${ }^{3}$, T. J. Smyth ${ }^{4}$, M. P. Utrillas ${ }^{1}$, and J. A. Martínez-Lozano ${ }^{1}$ \\ ${ }^{1}$ Dept. Física de la Terra i Termodinàmica, Universitat de València, C/ Dr. Moliner 50, 46100 Burjassot, Spain \\ ${ }^{2}$ Dept. Física Fundamental y Experimental, Electrónica y Sistemas, Universidad de La Laguna, Avda. Francisco Sánchez s/n, \\ 38200 San Cristóbal de La Laguna, Santa Cruz de Tenerife, Spain \\ ${ }^{3}$ Institute of Atmospheric Sciences and Climate, Italian National Research Council, Via Fosso del Cavaliere, \\ Roma Tor Vergata, Italy \\ ${ }^{4}$ Plymouth Marine Laboratory, Prospect Place, Plymouth PL1 3DH, UK \\ Correspondence to: V. Estellés (victor.estelles@uv.es)
}

Received: 9 November 2011 - Published in Atmos. Chem. Phys. Discuss.: 7 February 2012

Revised: 15 October 2012 - Accepted: 6 November 2012 - Published: 5 December 2012

\begin{abstract}
The European Skynet Radiometers network (EuroSkyRad or ESR) has been recently established as a research network of European PREDE sun-sky radiometers. Moreover, ESR is federated with SKYNET, an international network of PREDE sun-sky radiometers mostly present in East Asia. In contrast to SKYNET, the European network also integrates users of the CIMEL CE318 sky-sun photometer. Keeping instrumental duality in mind, a set of open source algorithms has been developed consisting of two modules for (1) the retrieval of direct sun products (aerosol optical depth, wavelength exponent and water vapor) from the sun extinction measurements; and (2) the inversion of the sky radiance to derive other aerosol optical properties such as size distribution, single scattering albedo or refractive index. In this study we evaluate the ESR direct sun products in comparison with the AERosol RObotic NETwork (AERONET) products. Specifically, we have applied the ESR algorithm to a CIMEL CE318 and PREDE POM simultaneously for a 4-yr database measured at the Burjassot site (Valencia, Spain), and compared the resultant products with the AERONET direct sun measurements obtained with the same CIMEL CE318 sky-sun photometer. The comparison shows that aerosol optical depth differences are mostly within the nominal uncertainty of 0.003 for a standard calibration instrument, and fall within the nominal AERONET uncertainty of 0.01-0.02 for a field instrument in the spectral
\end{abstract}

range 340 to $1020 \mathrm{~nm}$. In the cases of the Ångström exponent and the columnar water vapor, the differences are lower than 0.02 and $0.15 \mathrm{~cm}$, respectively. Therefore, we present an open source code program that can be used with both CIMEL and PREDE sky radiometers and whose results are equivalent to AERONET and SKYNET retrievals.

\section{Introduction}

An accurate characterization of atmospheric aerosols is required to better quantify the Earth's radiative balance and hence address issues such as climate change. The aerosol radiative forcing uncertainty is larger $\left(-0.6 \pm 0.4 \mathrm{~W} \mathrm{~m}^{-2}\right.$ for the direct effect) than the radiative forcing uncertainties due to greenhouse gases such as $\mathrm{CO}_{2}\left(1.8 \pm 0.2 \mathrm{~W} \mathrm{~m}^{-2}\right)$ (IPCC, 2007). This uncertainty needs to be reduced to enable more accurate predictions of future climate states.

To estimate aerosol parameters, the sun-sky radiometric technique is the most accurate and widely used. This technique consists of measuring two main variables at ground level: direct irradiance from the Sun, and diffuse radiance scattered from the sky. From the direct solar irradiance, an estimate of the aerosol optical depth (AOD) can be determined; this parameter can be considered the most simple parameter describing the aerosol burden in the atmospheric column 
(Holben et al., 1998). Using a combination of the direct sun and diffuse sky radiation, inversion algorithms can be applied to obtain other aerosol properties, such as the aerosol single scattering albedo, scattering phase function, refractive index and size distribution.

For climate data records, the World Meteorological Organization (WMO) only recommends the use of sun-sky radiometric data from international networks with imposed standardization leading to data product traceability. Such networks must provide a traceable calibration procedure, reliable quality standards and homogeneity in the retrievals within the network.

The best example of this is the NASA Aerosol Robotic Network (AERONET) (Holben et al., 1998), currently being the most extended operative network in the world. AERONET employs the CIMEL CE318 sky-sun photometer as the standard instrument, although different CIMEL versions coexist. More than 450 CIMEL units take part in the AERONET programme which adopts an original inversion algorithm to analyse the radiation components.

Another important international network is SKYNET (Takamura and Nakajima, 2004). SKYNET is a research network mostly situated in Asia. Currently, it is composed of nearly 70 sites in the world and it holds the POM sky radiometer, manufactured by PREDE CO. Ltd. (Japan) as the standard sky radiometer. SKYNET sites are considered basic or super sites, depending on complementary instrumentation present at the site. There are two models of PREDE sky radiometer, POM-01 and POM-02. The POM-01 model uses one Silicon photodiode sensor for wavelengths from 315 to $1020 \mathrm{~nm}$. The model POM-02 adds a InGaAs detector for extending the wavelength range at 1600 and $2200 \mathrm{~nm}$ wavelengths for cloud applications. The PREDE sky radiometer data is processed using the Skyrad.pack (Nakajima et al., 1996) code, currently at version 4.2 (Takamura and Nakajima, 2004) although version 5 will be used in the near future. This code is open source code, and therefore it can be used by the site managers in order to collaborate on the improvement and validation of the procedures.

The European Skynet Radiometers network (EuroSkyRad or ESR) (http://www.euroskyrad.net) has been recently established as a research and development network of European users of PREDE and CIMEL CE318 sky-sun photometers that focus their research on the atmospheric aerosols in Europe and the Mediterranean area. Currently, 12 sites take part in this network (Campanelli et al., 2012).

In contrast to both AERONET and SKYNET, the ESR does not hold any specific instrument as standard, but develops algorithms that can be applied to measurements from both instruments. In fact, one of the objectives of ESR is to perform synergistic studies with both networks and instruments. Keeping this instrument duality in mind, a new open source package (ESR.pack) has been developed. This package is greatly based on the Skyrad.pack algorithm used in
SKYNET, and has been modified, completed and adapted for application to CIMEL CE318 sky-sun photometers.

The ESR.pack consists of two modules for (1) the retrieval of direct sun products from the sun extinction measurements (aerosol optical depth, Ångström exponent and columnar water vapor); and (2) the inversion of the sky radiance to derive other aerosol properties (phase function, single scattering albedo, complex refractive index and aerosol size distribution). In this study, we describe and validate the first module (called sunrad), intended for the estimation of aerosol optical depth, Ångström wavelength exponent and columnar water vapor.

Two different versions or modes have been implemented in sunrad: mode 1 mostly employs routines and assumptions extracted from the Skyrad.pack source code (version 4.2). The retrievals obtained with mode 1 are therefore equivalent to SKYNET retrievals. In mode 2 we have implemented other routines that are much closer to those of AERONET direct sun algorithm (http://aeronet.gsfc.nasa.gov). The code we have developed can be applied to both CIMEL and PREDE instruments to retrieve aerosol properties equivalent to both AERONET and SKYNET retrievals.

In this work we have addressed the validation of the two modes of the sunrad module by (a) comparing the ESR (sunrad) and AERONET products using the same CIMEL CE318 sky-sun photometer database; (b) evaluating the differences between CIMEL and PREDE radiometers products obtained using the same ESR processing algorithm; and (c) comparing the ESR-PREDE products (results from the ESR code applied to the PREDE data) against AERONET-CIMEL products (results from the AERONET code applied to the CIMEL data).

\section{Instrumentation, calibration and methodology}

\subsection{Instrumentation}

The CE318 sky-sun photometer is an automatic ground based radiometer measuring both direct solar irradiance and diffuse sky radiance for almucantar and principal solar planes with a $1.2^{\circ}$ field of view limiting tube. The standard measuring schedule for this instrument broadly consists of direct sun measurements every $15 \mathrm{~min}$, and sky diffuse almucantar or principal plane scenarios every $30 \mathrm{~min}$. The direct sun measurements are performed three consecutive times, separated by around $20 \mathrm{~s}$. This triplet allows application of cloud screening filters based on the variability of the three consecutive readings. Although the channel wavelength configuration depends on the instrument version, filters at 440, 675, 870,940 and $1020 \mathrm{~nm}$ wavelengths are always present.

A CIMEL CE318 sky-sun photometer (polar version) was installed in January 2002 at the Burjassot campus of the University of Valencia in Spain $\left(39.51^{\circ} \mathrm{N}, 0.42^{\circ} \mathrm{W}\right.$, $\sim 30 \mathrm{~m}$ a.s.l.). During April 2007, the instrument started to 
operate within AERONET through the Red Ibérica de Medida de Aerosoles (RIMA) (http://www.rima.uva.es). This unit was serial number 422 and the filter wheel included channels at 440, 670, 870, 940 and $1020 \mathrm{~nm}$. In February 2009 , the optical head was upgraded to a UV version (filters at $340,380,440,500,675,870,940$ and $1020 \mathrm{~nm}$ ). From then on, other RIMA-AERONET units (serial numbers 424 and 425) have substituted unit 422 in this site although the nominal channels remained the same as unit 422 . Therefore, data from instruments 422,424 and 425 have been used in this study. The exact wavelengths are presented in Table 1 for the three units.

The PREDE POM-01 instrument is an automatic radiometer measuring direct sun and diffuse sky radiance with a $0.5^{\circ}$ field of view collimator tube at 7 channels: $315,443,500$, 675, 870, 940 and $1020 \mathrm{~nm}$. The PREDE POM design is broadly similar to CIMEL CE318 sky-sun photometer, although it performs direct sun readings every minute and solar almucantar plane sky radiance every 10 or $20 \mathrm{~min}$.

During January 2008, a PREDE POM-01L radiometer was installed at the Burjassot site, allowing us to compare both CIMEL and PREDE retrievals. For this study, we have only used direct sun measurements. The central wavelengths of the PREDE filters are shown in Table 1. It must be taken into account that 340,380 and $500 \mathrm{~nm}$ filters were not available for 422 CIMEL before February 2009. Due to previous filter degradation, the $940 \mathrm{~nm}$ filter was also changed at the same time. The wavelength in the table corresponds to the later filter. Moreover, standard POM instruments are equipped with a $400 \mathrm{~nm}$ filter, but the $440 \mathrm{~nm}$ filter was custom selected instead for a better match with the co-located CIMEL CE318 sky-sun photometer.

\subsection{Calibration}

Generally, in the ESR the calibration of CIMEL and PREDE CE318 sky-sun radiometers for the direct sun readings will be obtained on site by the application of an improved in situ Langley technique (SKYIL method) (Campanelli et al., 2004a). Tests of the method on a PREDE instrument in Rome showed a calibration accuracy of about $1.5-2.5 \%$, depending on the channel. Equivalent results were obtained for a CIMEL CE318 sky-sun photometer from Burjassot site (Campanelli et al., 2007). However, in order to exclude calibration effects in the present study, the PREDE calibration was in this occasion transferred from the CIMEL CE318 sky-sun photometers operating at the Burjassot site.

The CIMEL CE318 sky-sun photometers used in this study were calibrated by RIMA-AERONET. Pre- and postcalibrations were available for CIMEL units 422 and 424 . Only pre-calibration was available for unit 425 . Pre- and post-calibrations refer to calibrations performed before and after a measurement series. These calibrations are performed approximately on a yearly basis by a transfer from an AERONET master instrument (Holben et al., 1998). The
Table 1. Relation of wavelengths corresponding to central maximum for the filters employed by the CIMEL (units 422, 424 and 425) and PREDE sky radiometers (unit 046).

\begin{tabular}{lllll}
\hline Ch. & $\lambda_{\mathrm{c}, 422}(\mathrm{~nm})$ & $\lambda_{\mathrm{c}, 424}(\mathrm{~nm})$ & $\lambda_{\mathrm{c}, 425}(\mathrm{~nm})$ & $\lambda_{\mathrm{p}, 046}(\mathrm{~nm})$ \\
\hline 1 & - & - & - & 314.6 \\
2 & 339.3 & 339.3 & 338.6 & - \\
3 & 379.3 & 380.6 & 379.6 & - \\
4 & 440.8 & 438.2 & 437.9 & 443.7 \\
5 & 501.1 & 499.0 & 499.0 & 500.7 \\
6 & 675.0 & 672.5 & 674.5 & 675.3 \\
7 & 871.4 & 871.1 & 869.8 & 871.5 \\
8 & 939.8 & 935.0 & 937.5 & 940.2 \\
9 & 1019.2 & 1017.9 & 1019.5 & 1019.3 \\
10 & - & - & 1643.4 & - \\
\hline
\end{tabular}

nominal calibration uncertainty for field instruments can be estimated as $1-2 \%$, depending on the channel. The resultant uncertainty of the aerosol optical depth for an AERONET field instrument was estimated to be about $0.01-0.02$ (Eck et al., 1999) or about $10 \%$ for a nominal aerosol optical depth of 0.1 .

The calibration transfer consists of performing simultaneous direct sun measurements with two co-located instruments. In our case, the reference (or primary) instrument was the CIMEL, whose calibration was provided by RIMA. On selected days, the reference CIMEL is set to measure simultaneously with the PREDE (secondary instrument). These calibration transfers were periodically (every 1-3 months) performed after May 2009. Therefore, for the comparison between PREDE and CIMEL, we have not used data before this date. In order to reduce uncertainties introduced in the process, only cloudless and stable days were selected by visual inspection of the sky and the instrument readings, and the measurements were usually performed around solar noon to minimize rapid changes in the air mass. A typical PREDE transfer session consisted of the following: (a) a first leg of simultaneous one minute frequency measurements for approximately $1 \mathrm{~h}$; (b) cleaning of the optical head windows, checking of the collimator, and adjustment of the solar pointing system; (c) a second leg of measurements lasting approximately $1 \mathrm{~h}$. In this way, a post- and pre-calibration can be obtained from the first and second legs, respectively. These were then linearly interpolated to find a daily calibration for each day within the database.

If the instruments have a similar design and the differences in the central wavelengths are very small, then, to a good approximation, we can obtain the secondary calibration by applying

$F_{0}^{\mathrm{s}}\left(\lambda_{\mathrm{s}}\right)=F_{0}^{\mathrm{p}}\left(\lambda_{\mathrm{p}}\right) \frac{F^{\mathrm{s}}\left(\lambda_{\mathrm{s}}\right)}{F^{\mathrm{p}}\left(\lambda_{\mathrm{p}}\right)}$,

where $F$ and $F_{0}$ are the signal measured at ground and the extraterrestrial calibration, respectively. In this equation, the 
Table 2. Relation of algorithms implemented in the sunrad module in modes 1 and 2.

\begin{tabular}{lll}
\hline & mode 1 & mode 2 \\
\hline Solar coordinates & Skyrad 4.2 & Blanco-Muriel et al. (2001) \\
Refraction correction & No & Michalsky et al. (1988) \\
Sun-Earth distance & Skyrad 4.2 & Michalsky et al. (1988) \\
Optical mass & Single, plane parallel & Multiple; Kasten et al. (1989), Komhyr et al. (1989) \\
Rayleigh scattering & Fröhlich and Shaw (1980); Young (1981) & Bodhaine et al. (1999) \\
Ozone absorption & Skyrad 4.2 & Gueymard (2001) \\
Water vapor absorption & No & Gueymard (2001) \\
NO 2 absorption & No & Gueymard (2001) \\
Filter convolution & Gaussian function & Filter transmittance input file \\
Cloud screening & Smirnov et al. (2001) & Smirnov et al. (2001) \\
Temperature correction & Compensated (generic coefficients) & Compensated (generic or measured coeff.) \\
Ångström exponents & Ratio of wavelength pairs & Linear regression \\
Columnar water vapor & Bruegge et al. (1992); Halthore et al. (1997) & Bruegge et al. (1992); Halthore et al. (1997) \\
Meteo file input & Pressure and ozone & Pressure, ozone, NO 2 , water vapor, and air temperature \\
\hline
\end{tabular}

subscripts refer to the primary (p) and secondary (s) instrument channels. In Table 1 the different filters were compared for all the instruments employed in this study. The central wavelength differences between PREDE unit 046 and CIMEL's filters are lower than 1-2 $\mathrm{nm}$. The exceptions are at $440 \mathrm{~nm}$ and $940 \mathrm{~nm}$, with a difference of 5-6 $\mathrm{nm}$ in comparison to units 424 and 425 . In any case, these differences are smaller than the bandwidths (nominally $10 \mathrm{~nm}$ at the visible and near infrared range).

\subsection{Implementation of the sunrad module}

The ESR.pack is composed of two different modules: (a) sunrad, for deriving aerosol optical depth, Ångström exponent and columnar water vapor from the direct sun readings; and (b) skyrad, a modified version of the Skyrad.pack (Nakajima et al., 1996; Kobayashi et al., 2010) version 4.2, to invert the sky radiance measurements and obtain other aerosol properties such as size distribution, phase function, single scattering albedo and complex refractive index. In this section we will present the new sunrad module and the algorithms implemented within it. The software is programmed in FORTRAN. Deliverable versions of sunrad and skyrad programs will be eventually made public through the ESR website (http://www.euroskyrad.net).

Mirroring the structure of the Skyrad.pack software, the sunrad module has been implemented in two separate parts: a formatting program (dsform) reads the sky radiometer data files (from CIMEL or PREDE indistinguishably) and converts them to a data file whose format is independent of the instrument type; then, a processing program (dsproc) reads the formatted data files and retrieves the AOD and other columnar variables.

Both dsform and dsproc programs have been implemented in two different versions or modes: mode 1 mostly includes pre-existing subroutines from the Skyrad version 4.2, ex- tracted from the SKYRAD source code for homogeneity with SKYNET. In mode 2 we have implemented algorithms to derive the solar coordinates, optical mass, absorption coefficients and gaseous optical depths, based on previous published methods. These algorithms are similar to those implemented in version 2 of the AERONET direct sun algorithm (http://aeronet.gsfc.nasa.gov).

In Table 2 the differences between the mode 1 and 2 algorithms are listed. Mode 1 uses a single optical mass calculated for a parallel atmosphere, uses previous algorithms for the estimation of the Rayleigh scattering, and does not consider the effect of water vapor and $\mathrm{NO}_{2}$ absorption. Mode 1 also includes the convolution of gaseous absorption spectra by Gaussian transmission profiles calculated from the central nominal or exact wavelengths, and associated FWHM given in the configuration file. The Angström exponent is computed from the ratio of AOD at two different wavelengths for UV, VIS and NIR ranges. Specifically, in this study we have used the Angström exponent computed with the wavelengths $440 \mathrm{~nm}$ and $870 \mathrm{~nm}$.

The mode 2 algorithm dataset is based on the previous work of Estellés et al. (2006, 2007) and includes the following subroutines: a more accurate solar position algorithm (Blanco-Muriel et al., 2001) with the refraction correction of the solar zenith angle and the Sun-Earth distance given by (Michalsky et al., 1988); an optical mass based on Kasten et al. (1989) that is different for ozone calculation (Komhyr et al., 1989); and the computation of optical depths removing the effects of water vapor and $\mathrm{NO}_{2}$. The Ångström exponents are obtained by a linear fitting in the ranges UV, VIS and NIR for a more robust estimation (Martínez-Lozano et al., 1998). Specifically, in this study we have used the linear fitting in the range 440 to $870 \mathrm{~nm}$. Moreover, in this mode the real transmission profiles of the filters can be used to convolute the absorption coefficient spectra from all gases. 
For the retrieval of the columnar water vapor (CWV), the Bruegge et al. (1992) methodology with the generic coefficients proposed by Halthore et al. (1997) has been implemented. This methodology was actually employed in previous versions of AERONET direct sun algorithm version 1. Future developments of the ESR codes will include improved methodologies to derive the precipitable water content in mode 2, consistent with the AERONET version 2 methodology (http://aeronet.gsfc.nasa.gov). For mode 1, the method developed by Campanelli et al. (2010) will be used.

In order to quality assure the data and avoid cloud contamination, the basic Smirnov et al. (2001) cloud screening algorithm was also implemented in both modes. This is based on a set of criteria controlling the temporal variability of the AOD. This cloud screening method was designed for its use on CIMEL data, making use of the standard direct sun triplets used by this instrument. Therefore, its application to the CIMEL is straightforward.

To apply the Smirnov et al. (2001) algorithm to PREDE, sun measurements are performed once a minute. Triplets similar to CIMEL can be built during the data formatting stage in order to impose equivalent criteria. The CIMEL triplets are sets of three sun measurements performed in approximately $1 \mathrm{~min}$. Therefore, for the construction of PREDE triplets we select three consecutive measurements and interpolate them to obtain three measurements separated by $30 \mathrm{~s}$. These are considered to be the PREDE triplets and equivalent criteria on the short temporal variability of AOD can be applied.

Another important issue when comparing CIMEL and PREDE instruments is the temperature effect on the silicon photo-diode readings. The thermal coefficients depend on wavelength and can be estimated by experiments with a stabilized source lamp on a dark thermal chamber (Taviro, 2011). Our experiments for CIMEL unit 422 showed thermal coefficients only slightly different to those published by Holben et al. (1998).

Different methodologies to account for the temperature effect are used on both instruments. The CIMEL cannot control the sensor temperature, but it is routinely measured and can be corrected afterwards. In contrast, standard PREDE sky radiometers do not measure the sensor temperature, but the sensor is temperature stabilized. In the sunrad module, a subroutine for temperature correction is included. Generic thermal coefficients can be used for the most sensitive channels from CIMEL (1020 nm and $870 \mathrm{~nm}$ ) (Holben et al., 1998), but instrument specific coefficients can be used also, if available. Obviously, the correction is only applied when the sensor temperature is provided. This was not the case for our PREDE sky radiometer.

\subsection{Comparison methodology}

To perform the validation of the sunrad module (modes 1 and 2) with the AERONET direct sun algorithm version 2, the
CIMEL database obtained at Burjassot site (Valencia, Spain) has been used. More specifically, the study is limited to a subset spanning from April 2007 to June 2011 (for CIMEL) and May 2009 to June 2011 (for PREDE).

The pre- and post-calibrations for the CIMEL's were provided by RIMA/AERONET for units 422 (April 2007 to October 2009) and 424 (October 2009 to February 2011). Only pre-calibration is available for unit 425. As for AERONET, in the sunrad module the calibration for any given day is obtained by linear interpolation between pre- and postcalibration, and corrected by the Sun-Earth distance to get the effective calibration factor.

Daily values of the ozone columnar burden have been obtained from the OMI sensor and have been correspondingly interpolated for any instantaneous measurement (http:// ozoneaq.gsfc.nasa.gov). $\mathrm{NO}_{2}$ and water vapor were not available at this site, so they have been selected from published climatological values and standard atmospheres (Gueymard, 2001).

To estimate the gaseous absorption coefficients, we have employed the filter transmission profiles provided by the CIMEL and PREDE companies for our instruments (CIMEL unit 422 and PREDE unit 046). RIMA also provided new filters for unit 422 and other network instruments (units 424 and 425 ). In mode 2 , the real profiles were actually supplied in an input file and the absorption coefficients convoluted with them in the dsform program.

Level 2.0 products for unit 422 CIMEL were downloaded from the AERONET website (except AOD at $340 \mathrm{~nm}$, that only attains level 1.5 ). Only level 1.5 products were available for units 424 and 425 . Although level 1.5 data would be not appropriate for a climate data record, it is valid for comparison purposes. The evolution of AERONET AOD at $440 \mathrm{~nm}$ is shown in Fig. 1. The AOD seasonal evolution was in agreement with a previous $4 \mathrm{yr}$ climatology performed at this site (Estellés et al., 2007), with higher AOD during the summertime, and low values during the wintertime. The mean AOD at $440 \mathrm{~nm}$ during the data bench period was $0.18 \pm 0.11$, and the values vary from a background value of 0.08 (25th percentile) to occasional episodes overpassing 0.38 (95th percentile).

To estimate the deviation between sunrad module products and AERONET, different statistical indicators have been calculated: root mean square deviation (rmsd), mean bias deviation (mbd) and the standard deviation of differences (std). Equations (2) to (4) show these estimators. Ninety-fifth percentile and the rmsd expressed as a percentage were also computed. In the following expressions, $\tau_{0 i}$ and $\tau_{i}$ refer to the AOD from the reference and secondary instruments, respectively, and $\Delta_{i}$ represents the difference between two simultaneous $\tau_{0 i}$ and $\tau_{i}$.

$\mathrm{RMSD}=\sqrt{\frac{1}{N} \sum_{i=1}^{N}\left(\tau_{0 i}-\tau_{i}\right)^{2}}=\sqrt{\frac{1}{N} \sum_{i=1}^{N} \Delta_{i}^{2}}$ 


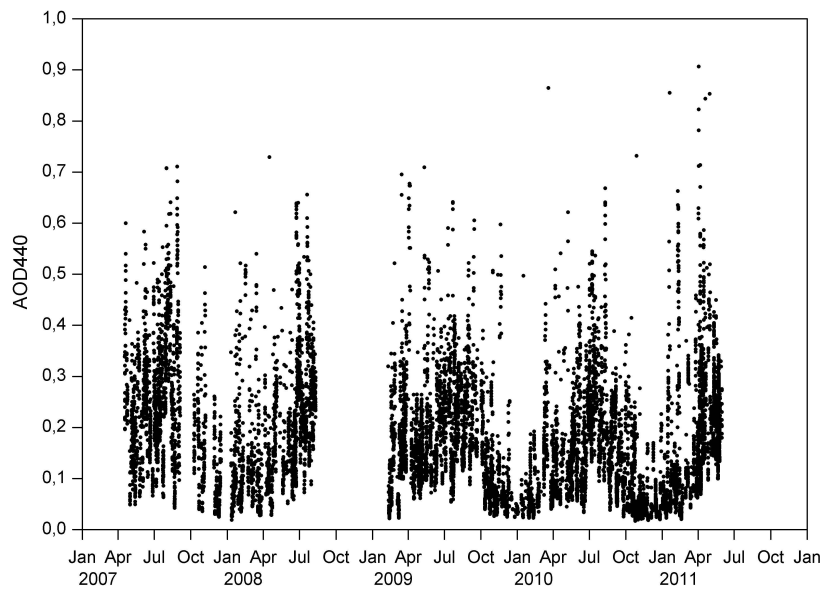

Fig. 1. Evolution of AERONET retrieved AOD at $440 \mathrm{~nm}$ in Burjassot (Valencia, Spain) during the period 2007-2011.

$$
\begin{aligned}
& \mathrm{MBD}=\bar{\Delta}=\frac{1}{N} \sum_{i=1}^{N}\left(\tau_{0 i}-\tau_{i}\right)=\frac{1}{N} \sum_{i=1}^{N} \Delta_{i} \\
& \mathrm{STD}=\sqrt{\frac{1}{N} \sum_{i=1}^{N}\left(\Delta_{i}-\bar{\Delta}\right)^{2}}
\end{aligned}
$$

Finally, the comparison between PREDE-ESR and the CIMEL-ESR or CIMEL-AERONET products have also been computed for all the coincident channels (including $440 \mathrm{~nm}$ and $443 \mathrm{~nm}$ pair, despite its larger wavelength displacement) using the same equations given above. Moreover, two PREDE and CIMEL measurements are considered coincident when the time difference between their acquisitions is less than $30 \mathrm{~s}$, and the Chauvenet criterion has been applied to avoid outliers in the samples by removing points with a difference from the mean greater than 3 times the sample standard deviation. The Chauvenet filter is addressed at avoiding particular situations such as temporal shadows or obstructions of any of the instruments.

\section{Results}

\subsection{Comparison of direct sun products from ESR and AERONET for the CIMEL sun photometer}

The performance of sunrad when applied to the same CIMEL CE318 sky-sun photometer analysed by AERONET has been assessed in this section. The same calibration factors and dataset have been used, so the differences between both products should be a minimum, related to the differences introduced by the software and not by the measurements. In Fig. 2, the differences (daily averaged) between ESR and AERONET for AOD675, AOD1020, Ångström exponent

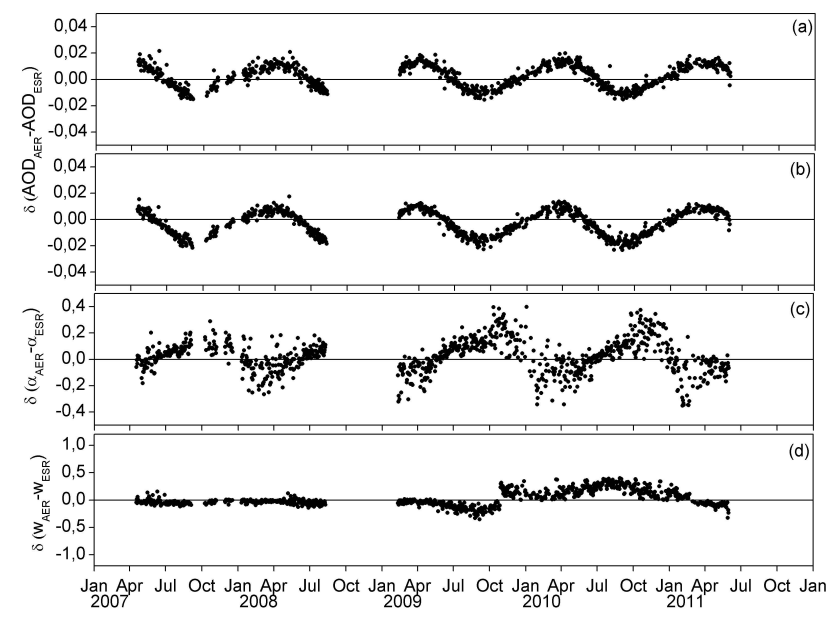

Fig. 2. Evolution of daily averaged differences between ESRCIMEL (mode 1) and AERONET products in Burjassot during period 2007-2011: (a) AOD at $675 \mathrm{~nm}$, (b) AOD at $1020 \mathrm{~nm}$, (c) Ångström exponent, and (d) columnar water content.

(AE) and CWV retrievals for mode 1 are shown. The statistics are presented in Table 3 (top table). In general, the AOD retrieved by sunrad (mode 1) is comparable with AERONET, getting mbd values between -0.0030 and 0.0041 ( 0.012 in the case of AOD340). The AOD differences are usually highest at $340 \mathrm{~nm}$ due to the higher signal to noise ratio in the UV region and uncertainties related to the estimation of the ozone optical depth. Moreover, the mbd signs show that the AOD is slightly underestimated by the sunrad (mode 1) algorithm, except for the 1020 channel.

The quadratic deviations (given by the rmsd) are higher, ranging from 0.0084 to 0.013 (0.018 in the case of AOD340). This increase in comparison to the mbd is related to a seasonal variability. This effect is strongly apparent in the temporal evolution of the differences, as shown in Fig. 2. These rms deviations are still below the AERONET estimated uncertainty for a field instrument (0.01-0.02 uncertainty depending on channel, higher at shorter wavelengths). The 340 and $440 \mathrm{~nm}$ channels are the exception, with an 95th percentile occasionally reaching or even surpassing this nominal uncertainty. Represented as a percentage, the AOD deviations vary between 5 to $11 \%$.

The former seasonal variations of the differences are produced by inaccuracies of the solar position and optical mass routines implemented in the sunrad mode 1 . The mode 1 air mass is only valid when the Earth curvature is ignored and if we assume that the atmosphere is non-refractive and homogeneous. Otherwise, the error is estimated $0.25 \%$ at a solar zenith angle of $60^{\circ}$ (Iqbal , 1983). The Michalsky et al. (1988) correction for refraction is not used in mode 1 , and would introduce less than $0.1 \%$ for a zenith angle of $70^{\circ}$. For the solar position, mode 1 uses the algorithm borrowed from the SKYRAD code. Unfortunately, information about the errors introduced by this algorithm are not available. 
Table 3. Statistics summary (root mean square deviation - absolute and expressed as percentage (\%), mean bias deviation, standard deviation of differences, and 95th percentile) between direct sun products obtained by ESR and AERONET from the CIMEL sky radiometer for mode 1 (top) and mode 2 (bottom). The number of data samples $(N)$ is also indicated. $N_{\mathrm{UV}}$ refers to the data available for 340 and 380 channels.

\begin{tabular}{lrrrrr}
\hline mode 1 & & & & $N_{\text {UV }}=613$ & $N=933$ \\
\hline & rmsd (\%) & rmsd & mbd & std & P95th \\
\hline AOD340 & 11 & 0.0179 & 0.0116 & 0.0137 & 0.0297 \\
AOD380 & 5.6 & 0.0126 & 0.0041 & 0.0120 & 0.0243 \\
AOD440 & 5.2 & 0.0109 & 0.0031 & 0.0104 & 0.0211 \\
AOD500 & 5.7 & 0.0097 & 0.0018 & 0.0095 & 0.0191 \\
AOD670 & 7.6 & 0.0095 & 0.0037 & 0.0087 & 0.0178 \\
AOD870 & 7.9 & 0.0084 & 0.0015 & 0.0082 & 0.0165 \\
AOD1020 & 11 & 0.0097 & -0.0030 & 0.0092 & 0.0187 \\
AE & 11 & 0.12 & 0.02 & 0.12 & 0.25 \\
CWV (cm) & 9.4 & 0.17 & 0.06 & 0.16 & 0.33 \\
\hline mode 2 & & & & & \\
\hline & & & & & \\
\hline AOD340 & 2.0 & 0.0051 & 0.0007 & 0.0050 & 0.0101 \\
AOD380 & 1.6 & 0.0036 & -0.0021 & 0.0030 & 0.0063 \\
AOD440 & 0.8 & 0.0016 & 0.0003 & 0.0016 & 0.0033 \\
AOD500 & 1.0 & 0.0018 & -0.0010 & 0.0015 & 0.0031 \\
AOD670 & 1.3 & 0.0016 & -0.0006 & 0.0015 & 0.0031 \\
AOD870 & 0.5 & 0.0005 & 0.0005 & 0.0002 & 0.0007 \\
AOD1020 & 2.2 & 0.0019 & 0.0002 & 0.0018 & 0.0037 \\
AE & 1.4 & 0.017 & -0.007 & 0.015 & 0.032 \\
CWV (cm) & 7.6 & 0.147 & -0.008 & 0.146 & 0.293 \\
\hline
\end{tabular}

For AE and CWV in mode 1, the rmsd is 0.12 and $0.17 \mathrm{~cm}$, respectively. The CWV uncertainty is related to the propagation of errors from $\mathrm{AE}$, the simplistic air mass calculation, and the lack of water vapor corrections in AOD1020 for mode 1 .

Figure 3 represents a scatter plot of the AOD values obtained by ESR and AERONET at the main CIMEL channels $(440 \mathrm{~nm}, 670 \mathrm{~nm}, 870 \mathrm{~nm}$ and $1020 \mathrm{~nm})$. In the scatter plots, the correspondent regression lines are also represented. The correlation coefficient is high in all cases $\left(R^{2}\right.$ higher than $0.99)$ and the slope is very close to 1 .

If switched to mode 2 , the results improve at all channels, especially for 340,440 and $870 \mathrm{~nm}$. Figure 4 shows the evolution of the differences. The improvement can also be detected in the 95th percentiles. The mbd is insignificant, ranging from -0.0021 to +0.0007 . In this case, the sunrad algorithm under- or overestimates, depending on the channel. The rms deviation ranges between only $0.0005-0.0018$, with the highest deviation in the UV channels (0.0051 for AOD340). For the VIS-NIR region, channel $1020 \mathrm{~nm}$ has the largest deviation (0.0019). This relative deviation could be related to uncorrected differences in the thermal constants or residual effects of the water vapor correction. In contrast to mode 1 , the standard deviation of the differences (std) is also very low (0.0002 to 0.0030 , only 0.0050 in the case of AOD340),

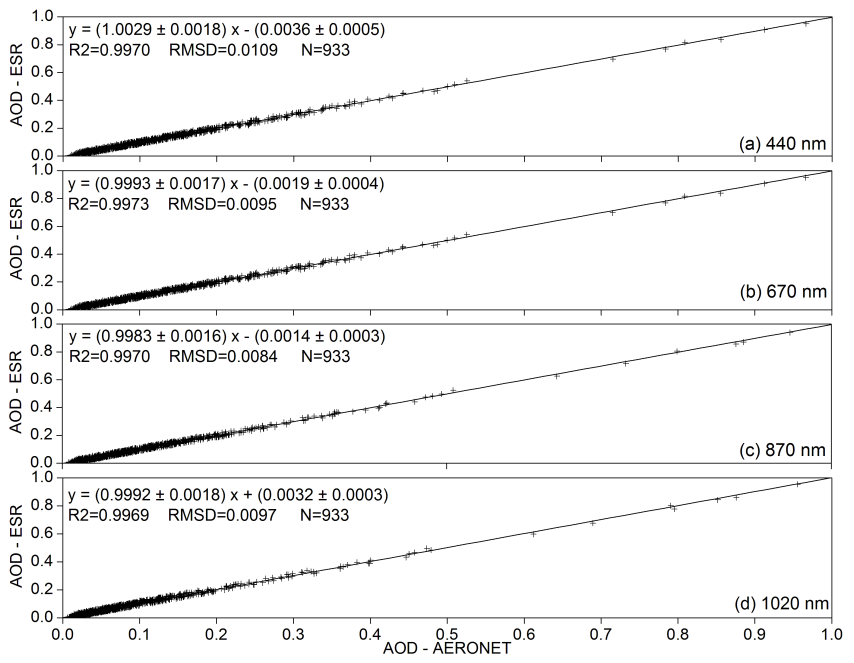

Fig. 3. Scatter plot and correspondent linear fitting for the AOD obtained by ESR and AERONET in mode 1 at (a) $440 \mathrm{~nm}$, (b) $675 \mathrm{~nm}$, (c) $870 \mathrm{~nm}$ and (d) $1020 \mathrm{~nm}$

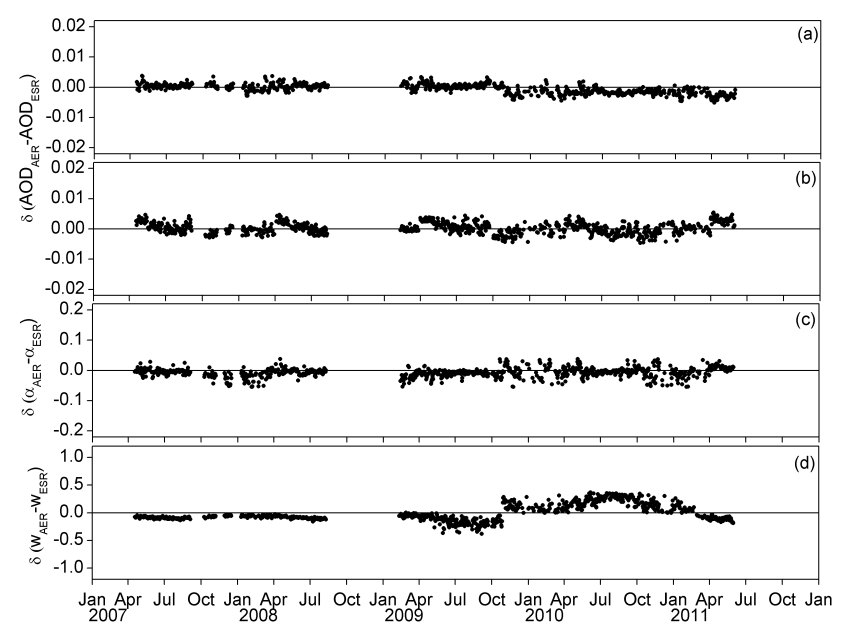

Fig. 4. Evolution of daily averaged differences between ESRCIMEL (mode 2) and AERONET products in Burjassot during period 2007-2011: (a) AOD at $675 \mathrm{~nm}$, (b) AOD at $1020 \mathrm{~nm}$, (c) Ångström exponent, and (d) columnar water content.

showing that the mean deviations are representative of the whole sample. In fact, the seasonal variability has completely disappeared, as can be seen in Fig. 4. On a percentage scale, the AOD deviation is found to be between 0.5 and $2.0 \%$.

Mode 2 optical mass expression is the same used by AERONET (Kasten et al., 1989) and it has been corrected by refraction (Michalsky et al., 1988). Therefore, the relative difference in mode 2 is now negligible. For the solar coordinates, mode 2 uses the PSA algorithm developed by Blanco-Muriel et al. (2001). In their article, Blanco-Muriel et al. (2001) state that the PSA algorithm is better than Michalsky et al. (1988) algorithm, with a standard deviation of the estimated error of $22 \%$ and $14 \%$ lower for the zenith and 


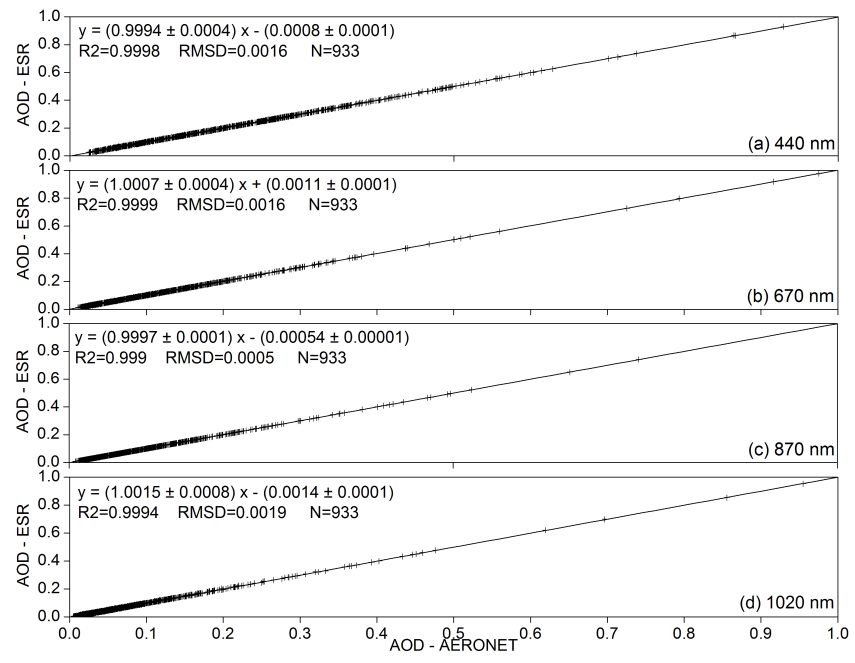

Fig. 5. Scatter plot and correspondent linear fitting for the AOD obtained by ESR and AERONET in mode 2 at (a) $440 \mathrm{~nm}$, (b) $675 \mathrm{~nm}$, (c) $870 \mathrm{~nm}$ and (d) $1020 \mathrm{~nm}$

azimuth angles, respectively, when they are compared to the Multiyear Interactive Almanac. This is a small improvement over Michalsky et al. (1988) method, and therefore, we expected a minor difference between AERONET and ESR in mode 2 but a larger difference when ESR was used in mode 1 .

The results are also better than mode 1 for $\mathrm{AE}$ and $\mathrm{CWV}$ parameters. For AE, the mbd and rms deviations are -0.007 and 0.017, respectively. The lower AOD and AE differences led to a mbd and rmsd of -0.008 and $0.15 \mathrm{~cm}$, respectively. Residual differences could be still decreased by changing the water vapor algorithm to the current version used in AERONET, using also individual constants for each $940 \mathrm{~nm}$ filter. In our case, only generic constants are assumed, based on the values given by Halthore et al. (1997).

In Fig. 5, the AOD obtained by the sunrad program is compared with the AOD obtained by AERONET for the main CIMEL channels $(440 \mathrm{~nm}, 675 \mathrm{~nm}, 870 \mathrm{~nm}$ and $1020 \mathrm{~nm})$ when mode 2 is used. The scattering around the fitted line is reduced in comparison to Fig. 3. The correlation coefficients are higher than 0.999 in all cases. The intercepts are even lower than the intercepts retrieved with mode 1, and the slopes are also very close to 1 .

\subsection{Application of the ESR software to CIMEL and PREDE instruments}

In this section our objective is to show that the provided software can be applied indistinguisably to both CIMEL and PREDE CE318 sky-sun radiometers, and the resulting retrievals are comparable. In this way, we can assure that measurements of AOD, AE and CWV performed by both instruments within the ESR network are homogeneous. Equivalent calibrations are used in order to isolate the effect of the instrumental differences. The effect of the calibration is
Table 4. Statistics summary (root mean square deviation - absolute and expressed as percentage (\%), mean bias deviation, standard deviation of differences, and 95th percentile) between the CIMEL and the PREDE when the same ESR software is used in mode 1 (top) and mode 2 (bottom). The number of data samples $(N)$ is also indicated.

\begin{tabular}{lrrrrr}
\hline mode 1 & & & & & $N=550$ \\
\hline & rmsd (\%) & rmsd & mbd & std & P95th \\
\hline AOD440 & 2.0 & 0.0038 & -0.0023 & 0.0030 & 0.0064 \\
AOD500 & 1.5 & 0.0025 & 0.0001 & 0.0025 & 0.0050 \\
AOD670 & 2.1 & 0.0022 & -0.0001 & 0.0022 & 0.0045 \\
AOD870 & 3.0 & 0.0026 & 0.0003 & 0.0026 & 0.0052 \\
AOD1020 & 5.3 & 0.0042 & -0.0013 & 0.0040 & 0.0080 \\
AE & 6.8 & 0.0772 & -0.0495 & 0.0592 & 0.1284 \\
CWV (cm) & 2.7 & 0.0520 & 0.0288 & 0.0433 & 0.0913 \\
\hline mode 2 & & & & & \\
\hline & & & & & \\
\hline AOD440 & 1.8 & 0.0034 & -0.0013 & 0.0032 & 0.0065 \\
AOD500 & 3.6 & 0.0057 & 0.0044 & 0.0037 & 0.0085 \\
AOD670 & 2.1 & 0.0023 & 0.0002 & 0.0023 & 0.0046 \\
AOD870 & 3.0 & 0.0026 & 0.0004 & 0.0026 & 0.0051 \\
AOD1020 & 5.7 & 0.0041 & -0.0006 & 0.0041 & 0.0082 \\
AE & 4.5 & 0.0537 & -0.0091 & 0.0530 & 0.1063 \\
CWV (cm) & 2.8 & 0.0528 & 0.0279 & 0.0449 & 0.0940 \\
\hline
\end{tabular}

currently under study; it is our aim to develop a calibration methodology that brings minimum differences between both instruments, and between our network and other networks such as SKYNET and AERONET.

Table 4 shows a statistical comparison between CIMEL and PREDE measurements, obtained with the same sunrad code and identical input parameters (ozone, atmospheric pressure), for modes 1 and 2 . No results are available for 340 and $380 \mathrm{~nm}$ channels because of different filter configurations between the instruments (Table 1). The database for this comparison is limited to PREDE and CIMEL matching years of 2009-2011.

The results presented in Table 4 show that equivalent AOD, AE and CWV retrievals are obtained with CIMEL and PREDE sky radiometers for both modes 1 and 2. For AOD, the mbd ranges between -0.0023 to +0.0044 in both modes, and the rmsd varies between 0.0022 and 0.0057 .

Maximum deviations are obtained for channels $1020 \mathrm{~nm}$ (probably due to residual temperature effects) and $500 \mathrm{~nm}$. The difference in $500 \mathrm{~nm}$ channel is a maximum when using mode 2, which is due to the exact filter transmission profiles that are used, in turn, to obtain the effective absorption coefficients of gases. It must be noted that the AOD is very sensitive to the effective absorption coefficients in some channels, dependent on the exact filter transmission shape (Kocifaj and Gueymard, 2011). Therefore, the methodology to obtain these coefficients has an impact on the final AOD obtained. In any case, the differences are always within the estimated uncertainties. 
The differences between both instruments are almost identical for both modes, and are slightly higher than the differences found in the previous section due to the increase of uncertainty on the calibration transfer to the PREDE, and the differences on the exact filter transmission profiles.

For $\mathrm{AE}$ and $\mathrm{CWV}$, the differences are also very low and independent of the mode, with an average rmsd of 0.006 and $0.05 \mathrm{~cm}$, respectively. In the case of CWV, the deviation is lower than the deviation obtained in the previous section. The $0.05 \mathrm{~cm}$ value would be a measure of the ability of the sunrad code to obtain water vapor columnar amounts from the PREDE instrument in comparison to CIMEL. This is a very useful result, as the PREDE sky radiometers are not currently used for the measurement of this important atmospheric variable.

New algorithms for the retrieval of CWV have been proposed during the past few years (Mavromatakis et al., 2007; Campanelli et al., 2010). The Mavromatakis et al. (2007) method proposes an improvement to the Bruegge et al. (1992) method for CIMEL instruments, and is expected to be implemented on the sunrad code for mode 2. The Campanelli et al. (2010) algorithm was proposed for its use on the SKYNET PREDE sky radiometers and currently is undergoing validation. This methodology will be implemented for mode 1, allowing for an accurate comparison between retrieval algorithms and instruments.

\subsection{Comparison of direct sun products from the PREDE (obtained by ESR) and the CIMEL (obtained by AERONET)}

Table 5 shows a statistical comparison between ESR-PREDE and AERONET-CIMEL retrieved parameters. The statistics have been estimated over 550 days distributed over $3 \mathrm{yr}$ for the period 2009-2011. No 340 and $380 \mathrm{~nm}$ channels are available for the comparison due to differences in the PREDE and CIMEL filter configuration.

Overall, Table 5 shows an acceptable agreement for mode 1 and a quite good agreement for mode 2 . The mbd for mode 1 spans from -0.0004 to +0.0057 , although the corresponding rms deviation is between 0.0085 and 0.0117 . The highest deviation corresponds to the $1020 \mathrm{~nm}$ filter. With a rms deviation of 0.15 and $0.20 \mathrm{~cm}, \mathrm{AE}$ and CWV deviations are comparable to previous Sect. 3.1.

Furthermore, mode 2 has a much lower deviation than mode 1 in comparison to AERONET. When mode 2 is selected, the rms deviation is kept low for AOD (0.00270.0054 for all channels) and AE (0.057). Even the 95th percentiles are maintained below this nominal uncertainty. On the contrary, the columnar water vapor reaches the limit of its estimated uncertainty $(0.20 \mathrm{~cm})$.
Table 5. Statistics summary (root mean square deviation - absolute and expressed as percentage (\%), mean bias deviation, standard deviation of differences, and 95th percentile) between PREDE direct sun products obtained by ESR and the CIMEL direct sun producs obtained by AERONET for mode 1 (top) and mode 2 (bottom). The number of data samples $(N)$ is also indicated.

\begin{tabular}{lrrrrr}
\hline mode 1 & \multicolumn{3}{r}{} & & $N=550$ \\
\hline & rmsd (\%) & rmsd & mbd & std & P95th \\
\hline AOD440 & 5.5 & 0.0103 & -0.0006 & 0.0103 & 0.0205 \\
AOD500 & 5.8 & 0.0094 & 0.0005 & 0.0094 & 0.0188 \\
AOD670 & 8.0 & 0.0089 & 0.0014 & 0.0088 & 0.0176 \\
AOD870 & 9.3 & 0.0085 & 0.0004 & 0.0085 & 0.0171 \\
AOD1020 & 14 & 0.0117 & -0.0057 & 0.0102 & 0.0212 \\
AE & 12 & 0.1496 & 0.0016 & 0.1496 & 0.2992 \\
CWV (cm) & 10 & 0.2009 & 0.1068 & 0.1701 & 0.3567 \\
\hline mode 2 & & & & & \\
\hline & & & & & \\
\hline AOD440 & 2.11 & 0.0039 & -0.0007 & 0.0038 & 0.0077 \\
AOD500 & 3.43 & 0.0054 & 0.0035 & 0.0042 & 0.0090 \\
AOD670 & 2.46 & 0.0027 & -0.0011 & 0.0024 & 0.0050 \\
AOD870 & 3.18 & 0.0027 & 0.0010 & 0.0026 & 0.0052 \\
AOD1020 & 5.70 & 0.0042 & -0.0005 & 0.0042 & 0.0083 \\
AE & 4.85 & 0.0570 & -0.0153 & 0.0549 & 0.1110 \\
CWV (cm) & 10.01 & 0.1953 & 0.0849 & 0.1759 & 0.3619 \\
\hline
\end{tabular}

\section{Discussion}

Only a few published CIMEL-PREDE studies are available for comparison with our results and all of them were performed by the application of different code to each instrument, usually for very short periods and with different ways of reporting the quantitative deviations.

Sano et al. (2003) reported a single day of intercomparison of CIMEL-AERONET and PREDE-SKYNET aerosol optical depths, with a deviation between both datasets of less than 0.008 at $670 \mathrm{~nm}$. Despite only a single day being presented, this value is very similar to ours for this channel when using mode 1 (rmsd of 0.0089) but higher than ESR on mode 2 (rmsd of 0.0027 ). No quantitative comparisons were provided for the other channels.

Campanelli et al. (2004b) performed a more detailed intercomparison between a CIMEL-AERONET and a co-located PREDE dataset using the Skyrad 4.2 inversion algorithm (mostly equivalent to ESR at mode 1) for a two-week period in Rome, Italy. The deviations expressed as percentage were $10-12 \%$, for a mean AOD at $500 \mathrm{~nm}$ of about 0.12 . The equivalent percentage rms deviation obtained by this work for the two-year CIMEL-AERONET and PREDE-ESR comparison has been $5.5-14 \%$ in the equivalent mode 1 . Mode 2 improved the difference to $2.1-5.7 \%$.

Evgenieva et al. (2008) presented an intercomparison exercise between a CIMEL-AERONET and PREDE-SKYNET at Belsk (Poland) over a period of two days. The lowest deviation was found at $675 \mathrm{~nm}$ channel, with an AOD relative 
difference of about $8 \%$. The corresponding deviation was found by us to be $8.0 \%$ in mode 1 .

In a more extensive study, Che et al. (2008) stated the need to perform more extended intercomparisons between these instruments in order to better address the differences between networks in Asia. This study was conducted in Beijing (China). For the direct sun readings, a total of 3169 instantaneous measurements retrieved during 220 days were used. In this case the deviation was reported as the relative difference of the mean aerosol optical depth for both databases, resulting in $0.91 \%$ at $440 \mathrm{~nm}, 1.03 \%$ at $670 \mathrm{~nm}, 1.27 \%$ at $870 \mathrm{~nm}$ and $0.82 \%$ at $1020 \mathrm{~nm}$.

Che et al. (2008) values are significantly lower than ours, whether we use mode $1(5-14 \%)$ or mode $2(2-6 \%)$. However, Beijing is characterized by frequent strong haze and dust dominated situations, with very high and extreme aerosol burdens (AOD at $440 \mathrm{~nm}$ frequently reaches extreme values such as 3.0). Therefore, the relative differences must be significantly reduced in comparison with our case, with a mean AOD at $440 \mathrm{~nm}$ of about $0.18 \pm 0.11$ and a percentile 95th of 0.38 (one order of magnitude lower than Beijing events). Unfortunately, the rmsd in absolute values were not reported in their work, and cannot be compared in our study.

In general, the mode 1 (SKYNET equivalent) PREDEESR against CIMEL-AERONET intercomparisons are equivalent to previously published values; we have considerably improved on the temporal and spectral representativity. Mode 2 has further improved on the mode 1 comparison, leading to measurements much closer to AERONET values.

\section{Conclusions}

In order to produce a valid climate data record, it is critical to use standardized and traceable data sources. AERONET is an operational international network devoted to the measurement of accurate aerosol properties, with a strong emphasis put on the traceability and homogeneity of the data.

Other international research networks have developed similar algorithms using open source code, such as SKYNET. However, SKYNET algorithms are adapted to a different radiometer, and therefore cannot be directly used with CIMEL instruments. To retrieve comparable aerosol properties, it is mandatory to use equivalent procedures for both instruments.

To overcome this difficulty, the European Skynet Radiometers network (ESR) has implemented a new algorithm package (called ESR.pack) that can be used in both AERONET and SKYNET standard instruments. In order to provide direct sun products equivalent to AERONET and SKYNET measurements, two versions or modes have been implemented, and their results have been compared with AERONET.

Eventually, the ESR package will be applied to all the PREDE POM and CIMEL CE318 sky-sun photometers from the ESR network. The objective of the network is to serve as a research platform where new techniques can be developed and validated, providing independent sites the benefit of a higher degree of homogeneity within the ESR network and comparable to other networks.

In this study, we have assessed the performance of the sunrad module in comparison to AERONET products. A fouryear database (2007-2011) of CIMEL measurements performed at the Burjassot site in Valencia (Spain) has been used for this purpose. The assessment performed with the CIMEL data shows that both sunrad modes can correctly reproduce the AERONET measurements well within the related uncertainties (maximum rmsd of 0.013), although mode 2 offers much lower differences than mode 1 , as expected (maximum rmsd of 0.0036). For water vapor, the rmsd was $0.17 \mathrm{~cm}$ and $0.15 \mathrm{~cm}$ for modes 1 and 2 , respectively.

The performance of sunrad code to obtain comparable products from both CIMEL CE318 and PREDE POM01 has also been studied. The differences when using both modes are also low, with a rmsd of 0.0022-0.0057, independent of the mode.

Finally, PREDE-ESR and AERONET AOD differ by a rmsd less than 0.012 and 0.0054 for modes 1 and 2, respectively, these results being obviously dependent on the homogeneity of the calibrations used in the radiometers.

Acknowledgements. The authors acknowledge RIMA and AERONET for providing data and CE318 calibration coefficients. We also thank K. Inei from PREDE CO. for his valuable advice on POM technical issues. V. Estellés thanks the Spanish Ministry of Science and Innovation (MICINN) for the research contract under the Juan de la Cierva programme (JCI-2009-04455). The Solar Radiation Group at the University of Valencia has been supported by projects CGL2011-24290 and CGL2009-07790 from the MICINN, and PROMETEO/2010/064 from the Valencia Autonomous Government. The GOTA group from the University of La Laguna was supported by the MICINN FORCAN project CGL2008-04740. T. J. Smyth was supported by NERC ADIENT (NE/E011144/1).

Edited by: E. Highwood

\section{References}

Blanco-Muriel, M., Alarcón-Padilla, D. C., López-Moratalla, T., and Lara-Coira, M.: Computing the solar vector, Solar Energy, 70, 431-441, 2001.

Bodhaine, B. A., Wood, N. B., Dutton, E. G. and Slusser, J. R.: On Rayleigh optical depth calculations, J. Atmos. and Ocean Tech., 16, 1854-1861, 1999.

Bruegge, C. J., Conel, J. E., Green, R. O., Margolis, J. S., Holm, R. G., and Toon, G.: Water Vapor Column Abundance Retrievals During FIFE, J. Geophys. Res., 97, 18759-18768, 1992.

Campanelli, M., Nakajima, T., and Olivieri, B.: Determination of the Solar Calibration Constant for a Sun-Sky Radiometer: Proposal of an In-Situ Procedure, Appl. Optics, 43, 651-659, 2004a. 
Campanelli, M., Gobbi, G., Tomasi, C., and Nakajima, T.: Intercomparison between aerosol characteristics retrieved simultaneously with a CIMEL and PREDE sun-sky radiometers in Rome (Tor Vergata AERONET site), Óptica Pura y Aplicada, 37, 3159_ 3164, 2004b.

Campanelli, M., Estellés, V., Tomasi, C., Nakajima, T., Malvestuto, V., and Martínez-Lozano, J.A.: Application of the SKYRAD Improved Langley plot method for the in situ calibration of CIMEL Sun-sky photometers, Appl. Optics, 46, 2688-2702, 2007.

Campanelli, M., Lupi, A., Nakajima, T., Malvestuto, V., Tomasi, C., and Estellés V.: Summertime columnar content of atmospheric water vapor from ground based Sun sky radiometer measurements through a new in situ procedure, J. Geophys. Res., 115, D19304, doi:10.1029/2009JD013211, 2010.

Campanelli, M., Estellés, V., Smyth, T., Tomasi, C., MartínezLozano, J. A., Claxton, B., Muller, P., Pappalardo, G., Pietruczuk, A., Shanklin, J., Colwell, S., Wrench, C., Lupi, A., Mazzola, M., Lanconelli, C., Vitale, V., Congeduti, F., Dionisi, D., Cardillo, F., Cacciani, M., Casasanta, G. P., and Nakajima, T.: Monitoring of Eyjafjallajoekull volcanic aerosol by the new European SkyRad users (ESR) sun-sky radiometer network, Atmos. Environ., 48, 33-45, doi:10.1016/j.atmosenv.2011.09.070, 2012.

Che, H., Shi, G., Uchiyama, A., Yamazaki, A., Chen, H., Goloub, P., and Zhang, X.: Intercomparison between aerosol optical properties by a PREDE skyradiometer and CIMEL sunphotometer over Beijing, China, Atmos. Chem. Phys., 8, 3199-3214, doi:10.5194/acp-8-3199-2008, 2008.

Dubovik, O. and King, M. D.: A flexible inversion algorithm for retrieval of aerosol optical properties from sun and sky radiance measurements, J. Geophys. Res., 105, 20673-20696, 2000.

Eck, T., Holben, B. N., Reid, J. S., Dubovik, O., Smirnov, A., O'Neill, N. T., Slutsker, I., and Kinne, S.: Wavelength dependence of the optical depth of biomass burning urban and desert dust aerosols, J. Geophys. Res., 104, 31333-31349, 1999.

Estellés, V., Utrillas, M. P., Martínez-Lozano, J. A., Alcántara, A., Olmo, F. J., Alados-Arboledas, L., Lorente, J., Cachorro, V., Horvath, H., Labajo, L., de la Morena, B., Vilaplana, J. M., Díaz, A. M., Díaz, J. P., Elias, T., Silva, A. M., Pujadas, M., and Rodríguez, J. A.: Aerosol related parameters intercomparison of CIMEL sunphotometers in the frame of the VELETA 2002 field campaign, Óptica Pura y Aplicada, 37, 3289-3297, 2004.

Estellés, V., Utrillas, M. P., Martínez-Lozano, J. A., Alcántara, A., Alados-Arboledas, L., Olmos, F. J., Lorente, J., De Cabo, X., Cachorro, V., Horvath, H., Labajo, A., De La Morena, B., Díaz, J. P., Díaz, A. M., Silva, Elías, T., Pujadas, M., Rodriguez, J. A., Cañada, J., and García, Y.: Intercomparison of spectroradiometers and sunphotometers for the determination of the aerosol optical depth during the VELETA2002 field campaign, J. Geophys. Res., 111, D17207, doi:10.1029/2005JD006047, 2006.

Estellés, V., Martínez-Lozano, J. A., Utrillas, M. P., and Campanelli, M.: Columnar aerosol properties in Valencia (Spain) by ground-based Sun photometry, J. Geophys. Res., 112, D11201, doi:10.1029/2006JD008167, 2007.

Evgenieva, T., Iliev, I., Koleva, N., Sobolewski, P., Pieterczuk, A., Holben, B. N., and Kolev, I.: Optical characteristics of aerosol determined by CIMEL, PREDE, and Microtops II sun photometers over Belsk (Poland), Proc. SPIE, 7027, doi:10.1117/12.822507, 2008.
Fröhlich, C. and Shaw, G. E.: New determination of Rayleigh scattering in the terrestrial atmosphere, Appl. Optics, 19, 1.773$1.775,1980$.

Gueymard, C. A.: Parameterized transmittance model for direct beam and circumsolar spectral irradiance, Solar Energy, 71, 325346, 2001.

Halthore, R. N., Eck, T. F., Holben, B. N., and Markham, B. L.: Sun photometric measurements of atmospheric water vapor column abundance in the $940 \mathrm{~nm}$ band, J. Geophys. Res., 102, 43434352, 1997.

Holben, B. N., Eck, T. F., Holben, B. N., Slutsker, I., Buis, J. P., Setzer, A., Vermote, E., Reagan, J. A., Kaufman, Y., Nakajima, T., Lavenu, F., and Smirnov, A.: AERONET - A federated instrument network and data archive for aerosol characterization, Remote Sens. Environ., 66, 1-16, 1998.

Iqbal, M.: An introduction to solar radiation, Academic Press, Ontario, 1983.

Intergovernmental Panel on Climate Change (IPCC), edited by: Solomon, S., Qin, D., Manning, M., Chen, Z., Marquis, M., Averyt, K. B., Tignor, M., and Miller, H. L.: Climate Change 2007: The Physical Science Basis. Contribution of Working Group I to the Fourth Assessment Report of the Intergovernmental Panel on Climate, 2007

Kasten, F. and Young, A. T.: Revised optical air mass tables and approximation formula, Appl. Opt., 28, 4735-4738, 1989.

Kobayashi, E., Uchiyama, A., Yamazaki, A., and Kudo, R.: Retrieval of Aerosol Optical Properties Based on the Spheroid Model, J. Meteorol. Soc. Japan, 88, 847-856, 2010.

Kocifaj, M. and Gueymard, C. A.: Theoretical evaluation of errors in aerosol optical depth retrievals from ground-based direct-sun measurements due to circumsolar and related effects, Atmos. Environ., 45, 1050-1058, 2011.

Komhyr, I. D., Grass, K. D., and Leonar, R. K.: Dobson spectrophotometer 83: a standard for total ozone measurements 1962-1987, J. Geophys. Res., 94, 9847-9861, 1989.

Martínez-Lozano, J. A., Utrillas, M. P., Tena, F., and Cachorro, V.: The parameterisation of the atmospheric aerosol optical depth using the Ångström power law, Solar Energy, 63, 303-311, 2007.

Mavromatakis, F., Gueymard, C. A., and Franghiadakis, Y.: Technical Note: Improved total atmospheric water vapour amount determination from near-infrared filter measurements with sun photometers, Atmos. Chem. Phys., 7, 4613-4623, doi:10.5194/acp7-4613-2007, 2007.

Michalsky, J. J.: The astronomical almanac's algorithm for approximate solar position (1950-2050), Solar Energy, 40, 227-235, 1988.

Nakajima, T., Tonna, G., Rao, R., Boi, P., Kaufman, Y., and Holben, B.: Use of sky brightness measurements from ground for remote sensing of particulate polydispersions, App. Opt., 35, 2672-2686, 1996.

Sano, I., Mukai, S., Yamano, M., Takamura, T., Nakajima, T., and Holben, B.: Calibration and validation of retrieved aerosol properties based on AERONET and SKYNET, Adv. Space Res., 32, 2159-2164, 2003.

Smirnov, A., Holben, B. N., Eck, T. F., Dubovik, O., and Slutsker, I.: Cloud screening and quality control algorithms for the AERONET database, Remote Sens. Environ., 73, 337-349, 2000 . 
Takamura, T. and Nakajima, T.: Overview of SKYNET and its activities, Óptica Pura y Aplicada, 37, 3303-3303, 2004.

Taviro, F.: Determination of the thermal coefficient from CIMEL CE318 sunphotometers, Degree project (in Spanish), Universitat de València, Burjassot, 46 pp., 2011.
Young, A. T.: On the Rayleigh scattering optical depth of atmosphere, J. Appl. Meteorol., 20, 328-330, 1981. 